\title{
EL FINAL DE LOS COMPLEJOS MUSTERIENSES Y LOS COMIENZOS DEL PALEOLÍTICO SUPERIOR EN EL SUR DE LA PENÍNSULA IBÉRICA
}

\author{
THE END OF THE MOUSTERIAN COMPLEXES AND THE BEGINNING OF THE \\ UPPER PALAEOLITHIC IN THE SOUTH OF THE IBERIAN PENINSULA
}

por

\author{
J. P. PANIAGUA PÉREZ*
}

RESUMEN En los últimos años el origen del hombre moderno se ha convertido en un tema de notable discusión. Es nuestra intención a continuación presentar de forma breve el estado actual del registro arqueológico y de la investigación, sobre este tema, en el sector meridional de la Península Ibérica. Por último se exponen los problemas presentados por los yacimientos del sur peninsular y las líneas de investigación que deberían ser confirmadas, desde nuestra perspectiva.

ABSTRACT In recent years, the origin of the modern man has become a notable subject of discusion. Our intention is to briefly show the present state of archaeological records and investigation on this subject in the southern area of the Iberian Peninsula. Finally we expound the problems presented in the sites of south of the peninsula with the lines of investigation that should be proved according to our perspective.

\section{INTRODUCCIÓN}

A comienzos de los años "setenta", cuando las diferentes series que conforman el Paleolítico Superior Inicial parecen ordenadas, los prehistoriadores empiezan a plantearse problemas que habían ocupado un segundo plano o ni siquiera habían sido considerados. Nos referimos a las dudas de cómo se producía la transición o el cambio de los complejos musterienses al Paleolítico Superior.

La transición es, fundamentalmente, un problema convencional (se trata de establecer rupturas en un continuo poblacional), aunque en el caso de Europa está cargado de significado porque este tránsito supone una serie de cambios y renovaciones importantes. El Paleolítico Superior significa una fuerte innovación

* Becario Predoctoral del Dpto. de Prehistoria e Historia Antigua de la Universidad Nacional de Educación a Distancia. 
en el plano tecnológico, tipológico, económico y social, además de incluir aspectos nuevos como se aprecia en el cambio étnico (los neandertales son sustituidos más o menos bruscamente por los hombres anatómicamente modernos) y en el desarrollo de las capacidades simbólicas.

Esta fuerte renovación supone la agrupación por parte de los investigadores en dos bandos totalmente opuestos, desarrollando sus modelos a partir de aspectos tanto culturales como biológicos (Stringer y Gamble 1993):

1.- Continuistas: son defensores de una etapa neandertal en la evolución de los humanos modernos. Sus orígenes están en los estudiosos del siglo XIX, como G. Schwalbe (que asignaba los restos de Neandertal y Spy a una especie ancestral que llamaba Homo primigenius) y D. Gorganovic-Kramberger (que estudió el material de Krapina). Durante los primeros años del siglo XX muy pocos eran partidarios de dar al hombre de Neandertal un lugar en la evolución, destacando entre ellos a A. Hrdlicka (1927) y F. Weidenreich, que desarrollaría un modelo que explicaba el origen de todas las razas modernas en el mundo entero, siendo los Neandertales, junto a sus semejantes en otras áreas del mundo, antepasados directos de la humanidad moderna. Este trabajo será la base de los futuros estudios de Brace y Wolpoff. La versión más moderna del esquema es el modelo Multirregional de Thorne y Wolpoff (Wolpoff 1986, 1989; Wolpoff et alii 1984, 1994) que, partiendo de los esquemas de centro y periferia, el flujo genético entre las poblaciones humanas resultó suficiente para contrarrestar la tendencia de los grupos periféricos (Europa, Java y Sur de África) a divergir significativamente de los demás.

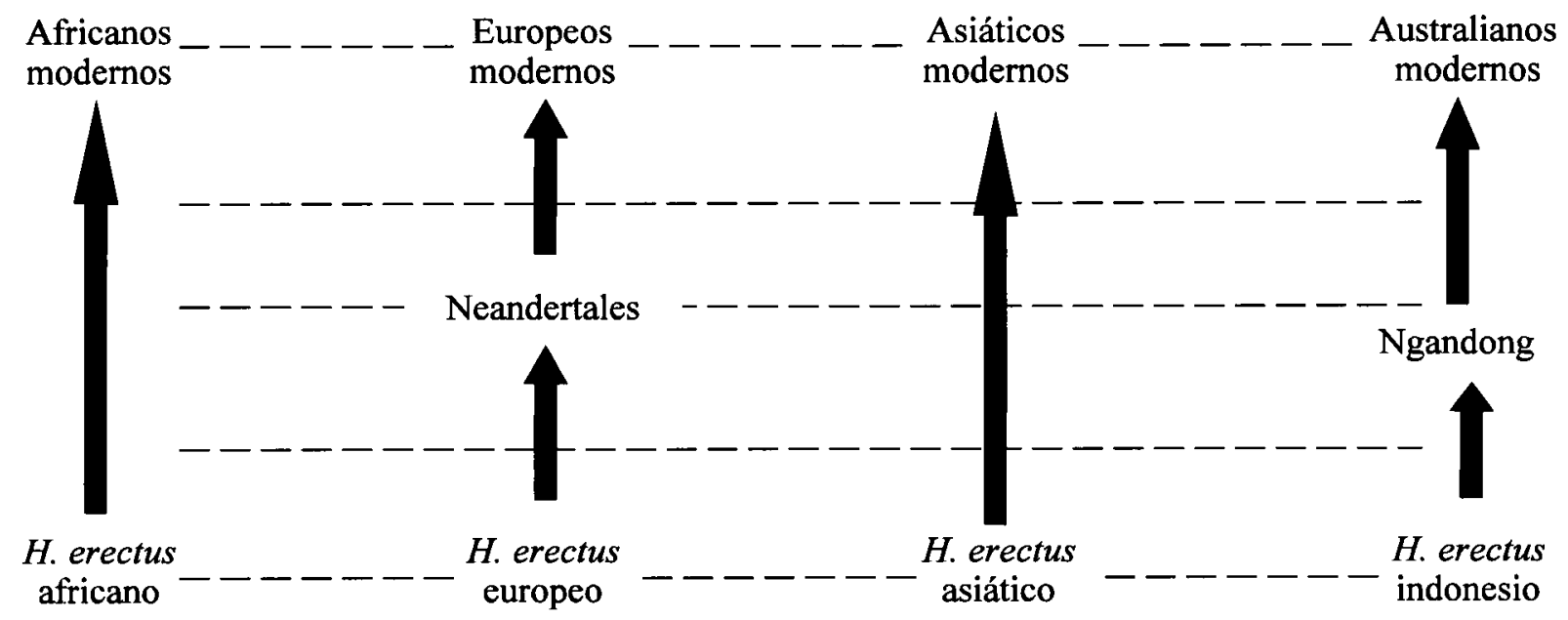

En el plano cultural, lógicamente, son partidarios de una sucesión entre el Musteriense y el Paleolítico Superior. Tradicionalmente se han basado en la posible filiación entre el Musteriense tipo Quina y el Auriñaciense (no probado todavía en nuestros días) y, sobre todo, en la continuidad entre el MTA tipo B y el Chatelperroniense, proceso prácticamente aceptado, pero lo que no se aprecia es la continuidad de este Chatelperroniense hacia formas culturales del Paleolítico Superior. Hoy en día se reivindican las antiguas cronologías para el Auriñaciense europeo y la fuerte carga del sustrato musteriense en el repertorio tipológico del Paleolítico Superior Inicial, como evidencias de continuidad. 
2.- Rupturistas: M. Boule fue el primero en negar un puesto de los Neandertales en la evolución humana pero el modelo "presapiens" fue desarrollado por un discípulo suyo, H. Vallois (1954), para el cual los avanzados rasgos que presentaba la humanidad moderna necesitaban de un largo período de gestación, por lo que situaba el antepasado común en hace un millón de años. El último modelo propuesto ha sido el de la dispersión desde África, desarrollado por W. Howells (1976), que postula la existencia de una única población ancestral reciente en una sola región del mundo (África) y todas las gentes modernas se derivaron de este grupo ancestral común mediante procesos de evolución y dispersión. En nuestros días, los máximos defensores de este modelo son, sobre todo, los genetistas (Cann 1988; Cann et alii. 1987; Stoneking y Cann 1989), aunque también se encuentran paleoantropólogos y prehistoriadores (Stringer 1988; Stringer y Andrews 1988; Stringer y Gamble 1993; Demars y Hublin 1989).

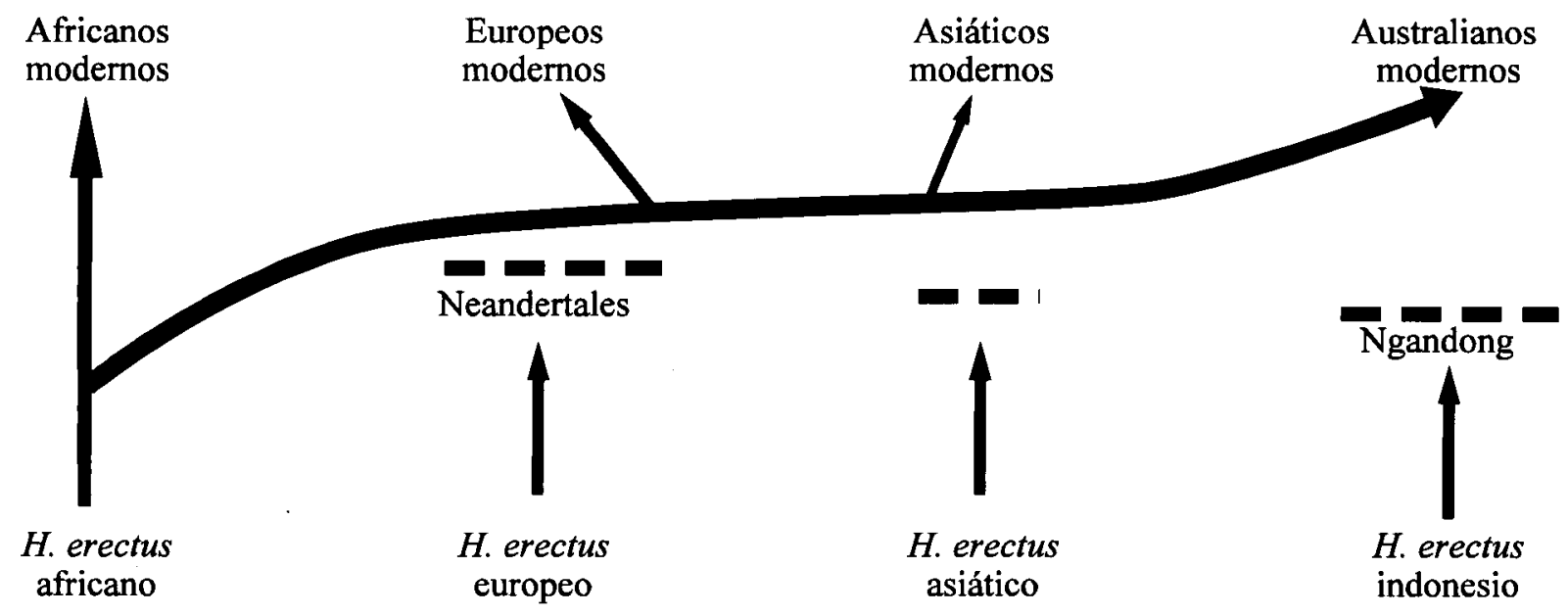

Son partidarios de una sustitución abrupta, tanto en el plano cultural como en el físico, partiendo de que el Paleolítico Superior se forma fuera de Europa y llega a ésta a través de los hombres modernos (Stringer y Gamble 1993).

La evolución del problema se irá debatiendo en una serie de congresos y reuniones científicas celebrados en estos últimos años, que irán marcando la pauta del desarrollo de la controversia que rodea a la transición. Por otra parte, la problemática de los orígenes del hombre anatómicamente moderno, que entra de lleno en el tema de la transición, ha originado todo un "boom" de estos estudios, palpable por medio de la avalancha de publicaciones, acompañadas de gran publicidad y celebraciones de congresos a ritmo anual que, prácticamente, no deja tiempo para asimilar la documentación generada.

\section{LA PENÍNSULA IBÉRICA}

Dentro de este panorama, la Península Ibérica esta aportando interesantes datos en los últimos años. Son numerosos los equipos que están trabajando en el problema de la transición, en yacimientos como la Cueva del Castillo (Santander), L'Arbreda (Gerona), el Abric Romani (Barcelona), la Cueva de la Carihuela (Granada) y la Cueva del Boquete de Zafarraya (Málaga), además de los interesantes trabajos y síntesis que sobre Portugal está llevando a cabo J. Zilhao (1993a y b). Estos yacimientos han confirmado datos 
que ya se conocían a nivel europeo, por ejemplo las antiguas dataciones para los comienzos del Aurinaciense, a la vez que se establece una interesante contradicción de eventos dentro de la misma Península Ibérica. Tres evidencias destacan:

— Los trabajos en los yacimientos del Norte peninsular (Cuevas de La Viña, El Castillo, L'Arbreda o el Abric Romani) confirman las antiquísimas dataciones para los orígenes del Auriñaciense, y el éxito de estas poblaciones en cruzar Europa, de Este a Oeste, en escasos dos o tres milenios.

- Por otra parte, los trabajos en el área mediterránea y sobre todo en el Sur peninsular, confirman que los Neandertales de estas regiones y sus complejos musterienses pervivieron de manera excepcional hasta bien entrado el Pleniglacial Superior Wurmiense. Esto, sumado a la inexistencia de industrias auriñacienses, supone un gran problema a la hora de intentar explicar el proceso de transición en esta región.

- Por último, fuera de la región cantábrica, donde queda atestiguada la presencia del Chatelperroniense, no se documenta ningún tipo de interacción entre ambas poblaciones, pudiéndose apreciar por contra unos musterienses muy estáticos en lo tecnológico con pocas variaciones en sus costumbres.

Estas evidencias, sin embargo, no han desembocado en un común acuerdo de los investigadores, que han desarrollado diferentes interpretaciones del problema, alineándose en una de las dos corrientes que lideran la transición a nivel europeo y mundial:

- Continuistas: las elevadas cronologías de los yacimientos del Norte, sumado a la interpretación de elementos culturales, les lleva a defender una transición in situ de los complejos musterienses al Paleolítico Superior durante el Würm II-III (Cabrera 1996; Cabrera y Bernaldo de Quirós 1990, 1993, 1996; Cabrera y Bischoff 1989).

- Rupturistas: prácticamente todos los investigadores del país, partidarios de una ruptura total del Paleolítico Superior con el mundo anterior, además de la imposición de nuevos sistemas culturales y de un nuevo tipo racial (Maroto y Soler 1990; Soler y Maroto 1990, 1993; Maroto et alii. 1996; Terradas et alii. 1993; Iturbe et alii. 1993; Vega 1993; Maroto 1994).

\section{EL REGISTRO ARQUEOLÓGICO DEL SUR DE LA PENÍNSULA IBÉRICA}

El registro arqueológico de esta zona para los momentos que nos interesan no está exento de problemas: - Estratigráficos: las grandes secuencias de la región confirman la pervivencia de los neandertales, pero carecen de niveles transicionales donde podamos estudiar lo sucedido.

- Ausencia, con excepción de la Cueva de la Carihuela, de estudios paleoambientales, paleontológicos, litoestratigráficos, palinológicos, etc... que permitan la interpretación paleoecológica de los diferentes yacimientos, y su comparación cronoestratigráfica dentro de un marco regional.

- Por último, las limitaciones características de la ausencia de excavaciones referidas al momento estudiado (tan sólo los proyectos de las cuevas de Carihuela y Zafarraya, más el desarrollado en Gibraltar por los investigadores ingleses), como la ausencia de publicaciones de los pocos yacimientos que se excavan (recordemos que Carihuela y Zafarraya llevan años pendientes de publicar una monografía), y el manejo de datos de intervenciones antiguas desarrolladas en algunos yacimientos de interés, complican mucho el intento de desarrollar una síntesis. 


\subsection{Historia de las investigaciones}

El inicio de las investigaciones prehistóricas en la región meridional de la Península Ibérica procede de mediados del siglo pasado con las recolecciones fosilíferas de las canteras y cuevas del Peñón de Gibraltar, mientras se acondicionaba la colonia como base militar. El hallazgo del cráneo de Forbe's Quarry supone el descubrimiento del primer homínido fósil de la Prehistoria. Durante el siglo pasado, el punto más importante será el curso que el geólogo J. Vilanova i Piera ofrecerá en la Universidad de Sevilla en 1872 y que significará la introducción en el país de la ciencia prehistórica, tal y como había sido definida en otros países europeos (Ayarzaguena 1991).

En este mismo siglo, el primer impulso serio para la investigación prehistórica viene dado por L. Siret, primer sistematizador de la prehistoria del Sureste. Al igual que en las épocas de los metales, también destacó en los trabajos sobre Paleolítico, aunque la diferencia en publicaciones es notable. Ello no motivó que carecieran de calidad. Tal es así que, gracias a sus artículos, ya clásicos, los yacimientos del Sureste empezaron a ser incluidos en las sistematizaciones generales que prehistoriadores extranjeros realizaban. Insertado dentro del contexto africanista de comienzos de siglo, en su artículo de 1931 titulado "Classification du Paléolithique dans le Sud-Est de l'Espagne", no duda ni un instante en considerar el registro peninsular como europeo y no africano como se estaba imponiendo en su momento. Entre el legado que Siret nos dejó, destaca el enorme número de yacimientos encontrados y excavados (Zájara I y II, Serrón, Los Morceguillos, Cueva de Ambrosio, en Almería; Perneras, Palomarico y Vermeja, en Murcia) en el área del Sureste y sus materiales conocidos como Colección Siret custodiada en el Museo Arqueológico Nacional.

Acto seguido a Siret, serán H. Obermaier y H. Breuil en los tres primeros decenios de siglo los que estudien y descubran nuevas cuevas con arte, además de realizar diferentes trabajos en distintos yacimientos. En concreto, será H. Obermaier en 1934 quien realice un nuevo estudio sobre el Paleolítico de Andalucía, labor que se centró en una serie de prospecciones por la provincia de Granada en las que destaca la recogida de materiales procedentes del desmantelamiento de la entrada de la Cueva de la Carihuela, depositados en lo que se conoce como Fuente de la Zarza, es decir, no llegó a conocer el yacimiento. En este trabajo tildaba estas industrias de Musteriense evolucionado, mezclado con Neolítico y Capsiense (Vega 1988). De esa misma época, constan también los trabajos de M. Such en la Cueva del Higuerón que publicará con metodología muy moderna para la época (Such 1920).

A continuación, se desarrollarán en Andalucía los que, en nuestra opinión, se pueden considerar años oscuros del Paleolítico andaluz y que coinciden, en líneas generales, con los años ' 40 y ' 50 durante los cuales se abandona el impulso dado por los "grandes" clásicos y nadie recogerá el testigo. Como ejemplo de la oscuridad de estos años, destacamos los diferentes "agujeros" que fue realizando el investigador suizo J. Ch. Spanhi en algunos yacimientos de Granada (Cueva de Carihuela o Cueva Horá), "trabajos", que nunca fueron publicados.

En los años sesenta, una serie de programas se harán cargo de importantes yacimientos algunos de ellos desconocidos, que no significa la salida del período anterior. Entre las excavaciones que se inician en estos años destacan Cueva de Ambrosio, dirigida por E. Ripoll (1961), la recién descubierta Cueva de Nerja, en la que inmediatamente empieza a trabajar M. Pellicer y le seguirá A. M ${ }^{a}$ de la Quadra Salcedo, Cueva Horá, dirigida por M. Pellicer, Cueva de la Carihuela (Almagro Basch et alii 1970) bajo el proyecto de la Washington State University, y por la que ya habían pasado con anterioridad Spanhi y Pellicer.

Por último, una nueva etapa se vivirá a partir de mediados los años ochenta, con el traspaso de las competencias, en materia de patrimonio histórico-arqueológico, a las Comunidades Autónomas. El panorama andaluz apunta muy alto con la concesión de importantes y ambiciosos proyectos que, con el paso del tiempo, han ido perdiendo peso por cuestiones, fundamentalmente, económicas. Entre los proyectos aprobados y concedidos en estos años están los centrados en la Cueva de la Carihuela, dirigido por G. Vega Toscano, o el de la Cueva del Boquete de Zafarraya, dirigido por C. Barroso y J. J. Hublin. 


\subsection{Los yacimientos}

3.2.1.- Cueva de la Carihuela (Píñar, Granada): mencionada por primera vez por H. Obermaier (1934), tras las prospecciones que realiza en la provincia de Granada a principios de siglo, serán numerosos los investigadores que han trabajado en el yacimiento así como los que han estudiado sus distintas colecciones. Entre los trabajos realizados deben destacarse los de la Washington State University bajo la dirección de H. T. Irwin y B. Fryxell (1969), ya que fue el programa que dejó sentadas las bases para su posterior desarrollo en los años ' 80 . Por último, en 1979, se presenta el proyecto que en la actualidad se desarrolla y que dirige G. Vega Toscano. En líneas generales, sigue muchas de las propuestas planteadas por el anterior programa, siendo estructurado en tres fases: analítica de los materiales recuperados por los americanos; excavaciones limitadas para resolver problemas planteados en la primera fase, evitar el derrumbe de algunos cortes y practicar sondeos para completar el conocimiento del depósito y, si las fases anteriores avalan, excavar en extensión para realizar estudios paleoetnográficos con garantías (Vega 1988).

Respecto al relleno de la cueva, la estratigrafía de Carihuela presenta ciertos problemas, hasta el punto de que algunos de ellos no han sido resueltos en la actualidad (las "cicatrices" erosivas). Además de estos problemas, la cueva presenta diferentes cortes, no siempre fáciles de correlacionar, incluso todo el relleno se debe a dos aportes principales, procedentes de áreas diferentes que contactan en la parte central de la cueva. Pensamos que la mejor descripción de la estratigrafía del yacimiento se encuentra en la Tesis Doctoral de Vega (1988), por lo que nos remitimos a ella. Sin embargo, sí haremos una aproximación cronológica de este relleno; la secuencia conocida de Carihuela contiene doce unidades litoestratigráficas, en las que se puede individualizar un centenar de niveles: unidades XII-XI, último interglaciar y Würm Inicial (fase isotópica 5), unidades X-VIIb, Pleniglacial Inferior wurmiense, unidades VIIa-VI, Interpleniglacial, unidades V-III, Pleniglacial Superior y unidades II-I Holoceno (Vega et alii. 1988; Vega 1988, 1990, 1993). Recientemente, la publicación del estudio palinológico confirma esta secuencia paleoclimática (Vega y Carrión 1993). Por último, comentar que el registro de Carihuela comprende en una escala casi continua, los eventos culturales, ambientales, antropológicos y paleontológicos, de todo el Pleistoceno Superior y el Holoceno (Vega 1993).

En el momento de tratar los materiales de la Cueva de Carihuela, lo primero que hay que tener en cuenta es que, es "...imposible evaluar la totalidad de las colecciones desperdigadas..." (Vega 1988). Aparte de las diferentes colecciones depositadas en varios Museos, se sabe de la existencia de colecciones privadas, al igual que de la desaparición de materiales significativos de las campañas 1969-71. A esto habría que añadir que las colecciones de Spanhi son inservibles por su enorme selección como por sus problemas de adscripción estratigráfica y las procedentes de las campañas de los americanos no son utilizables debido a su origen en limpiezas de cortes y áreas revueltas, además de haber sido obtenidas por niveles (tallas) artificiales (Vega 1988).

El material paleontológico carece de un estudio definitivo por lo que sólo se dispone, de momento, de una determinación de especies para la macrofauna. La microfauna y los quirópteros fueron estudiados por Ruiz Bustos y Sevilla, respectivamente, partiendo de las matrices depositadas en el Museo de Granada procedentes de las excavaciones de Spanhi, en el primer caso, y de las de Irwin, en el segundo. La lista determinada, hasta el momento, presenta un amplio repertorio de especies, entre los se encuentran dos tipos de équidos, dos de rinoceronte, ciervo, cabra, bóvido, lobo, zorro, oso, pantera, hiena, lagomorfos y una larga lista de micromamíferos, quirópteros y aves. Pendientes de un estudio más profundo, es imposible hacer planteamientos respecto a los acumuladores de los restos como referentes a las actividades económicas de los grupos humanos.

Respecto a los restos líticos, el estudio de la industria de Carihuela se ha realizado sobre las 37 series que proporcionó el corte III, con un total de 50900 restos líticos. En el aspecto técnico, los índices, calculados por el método Bordes, son muy homogéneos; todas las series son no levallois (índice medio de 7,16 ) y 
facetadas (IF. 59,49, y IFs. 38.93), los índices laminares son bajos (Ilam. 7,87). La clasificación, partiendo del empleo de la técnica Bordes, se realiza con base en las variaciones tipológicas. De esta forma, se han podido diferenciar las siguientes industrias (Vega 1988):

Musteriense Típico: presente en 28 de las 34 series en las que se ha podido establecer una clasificación. Según los diferentes índices tecnológicos, se han establecido cuatro tipos de Musteriense Típico.

Charentiense de tipo Zájara: son niveles que entran dentro de la variabilidad charentiense aunque, desde una perspectiva ortodoxa, serían híbridos entre los tipos Quina y Ferrassie ya que tienen un índice quina bajo, están bien facetadas y no llegan a ser levallois. Este tipo de charentiense fue definido a comienzos de los ochenta en la Cueva de Zájara I (Vega 1980).

Musteriense de denticulados: está presente en sólo dos series, una de ellas problemática, y la otra presenta un $57,7 \%$ de denticulados.

Es importante destacar que a lo largo de la secuencia y, sobre todo, en su parte final, no se observan elementos que hagan pensar en una evolución hacia el Paleolítico Superior (Vega 1980).

A nivel cronológico, el proyecto de los americanos contemplaba la realización de dataciones, que se llevaron a cabo utilizando el método de la Termoluminiscencia cuando todavía era un sistema experimental. Hay todo un repertorio de dataciones que se pueden ver en la Tesis de Vega (1988), destacando la datación de la Unidad XII, que se sitúa en torno a 82000 BP, y la Unidad IV; en 13000 BP. Actualmente, se ha realizado una nueva serie de dataciones que vienen a confirmar, en líneas generales, que la secuencia conocida de Carihuela abarca todo el Pleistoceno Superior (Vega, comunicación presentada al Simposio de Prehistoria de Nerja, Mayo 1996).

3.2.2.- Cueva Horá (Darro, Granada): situada en el extremo oriental de Sierra Harana, como yacimiento paleolítico se conoce desde 1916, momento en que H. Obermaier la exploró (Obermaier 1934), señalando que el relleno ya había sido saqueado y destacando la presencia de un "Musteriense fino" (Vega 1988). Cuarenta años más tarde, J. Ch. Spanhi realizó una intervención en el yacimiento por medio de varias catas, pero los resultados obtenidos nunca fueron publicados. Un año más tarde M. Pellicer realiza un sondeo en el que llega a una profundidad de $8 \mathrm{~m}$, sin llegar a la roca madre, y del cual se realiza la primera descripción de la estratigrafía (Pellicer 1964) y, más tarde, se estudia la fauna (Fuentes y Meijide 1975). Esta colección obtenida por Pellicer ha sido estudiada en más de una ocasión, destacando la realizada por Toro y Almohalla (1979) que vieron en los restos del estrato III un Auriñaciense. Por último, los trabajos más importantes se desarrollaron en el yacimiento entre 1977 y 1985 , dirigidos por M. Botella, de los que se ha publicado un avance de las dos primeras campañas (Botella y Martínez 1979) y las características de las colecciones de una serie de niveles (Botella et alii 1983; 1986), además del estudio geológico (Rodríguez y Martín 1979) y paleontológico. De esta intervención debe destacarse los más de $15 \mathrm{~m}$ de profundidad alcanzados, sin llegar a tocar roca madre, lo que indica la impresionante potencia que debe tener el relleno sedimentario de la cueva.

La estratigrafía del yacimiento carece de una síntesis total y definitiva, estando estudiado únicamente el conjunto superior de las excavaciones de $\mathrm{M}$. Botella, lo que supone los tres primeros metros de la secuencia. Además, hay que añadir que no hay correlación, o no se ha intentado correlacionar, entre los niveles de la excavación de Pellicer y la de Botella. Por lo tanto, de los trabajos provisionales (Rodríguez y Martín 1979) sobre la geología del lugar se puede concluir que sólo hay una auténtica estratificación a techo del depósito, lo que se corresponde con los dos primeros metros, para desarrollarse, a continuación, un relleno de limos arenosos con bloques y gravas angulosas, repartidos ambos materiales de forma irregular. A nivel cronoestratigráfico, pocas matizaciones se pueden hacer para los autores (Rodríguez y Martín 1979): la parte de secuencia analizada se correspondería con una fase fría, más o menos húmeda, con oscilaciones. Respecto al resto del depósito, la carencia de estudios imposibilita cualquier interpretación o correlación (Vega 1988). 
La dinámica de formación del yacimiento (la actuación de la dolina superior, como colector que recoge las escorrentías de ladera) hace que se deban tener en cuenta una serie de aspectos: imposibilidad de encontrar restos arqueológicos y paleontológicos en posición in situ debido, fundamentalmente, a que los restos abandonados tenderán, progresivamente, a desplazarse hacia la pendiente exterior, con la consecuente mezcla de materiales que esto origina; por los mismos motivos, no es un registro ideal para establecer un modelo cronoestratigráfico por la imposibilidad de situar los límites de estratos y la contemporaneidad de los restos que en ellos se encuentran (Vega 1988).

Los materiales de la cueva, para seguir con la dinámica del yacimiento, no están exentos de problemática. Existen varias colecciones (Obermaier, Spahni, Pellicer y Botella), con escasas referencias estratigráficas e, incluso, de alguna colección se desconoce si los materiales proceden de la estratigrafía, de la superficie o de la ladera, por no citar las que no se han encontrado, como es el caso de la Colección de Obermaier. Por último, debe tenerse en cuenta que la excavación de Cueva Horá supone un trabajo sin terminar y que sólo se tienen noticias inconexas y provisionales. De las diferentes colecciones, la que presenta interés de cara al problema que aquí analizamos es la de Pellicer, en cuyos materiales unos autores (Toro y Almohalla 1979) vieron un Auriñaciense. Pellicer diferenció ocho estratos en la parte de secuencia que excavó, de los que los cinco superiores se corresponderían con un Epipaleolítico y los tres inferiores pertenecerían a un Musteriense sin determinar. Según los autores antes mencionados, parece ser que Pellicer matizó, aunque siempre de forma oral, en varias ocasiones que el nivel III sería un Auriñaciense. La base de esta interpretación la constituyen un lote de cuatro raspadores, una pieza truncada y seis láminas, una de ellas con retoque continuo sobre un borde y otra auriñaciense (Toro y Almohalla 1979). Sin embargo, tras la revisión realizada por Vega, aparecieron una serie de problemas: efectivamente, existen los raspadores comentados por Toro y Almohalla, al igual que la hoja auriñaciense, pero la truncatura para Vega no es una, sino varias (Vega 1988), la composición tipológica dista mucho de un Auriñaciense ya que están ausentes los raspadores carenados o en hocico y, además, no hay industria ósea ni elementos musterienses que suelen aparecer en este contexto. Por último, y lo más importante, la presencia de un fragmento de cerámica realizada a mano entre los materiales del Estrato III de Pellicer, y que Toro y Almohalla no vieron, tira por tierra la existencia de Auriñaciense en el yacimiento (Vega 1988).

Respecto a la fauna del yacimiento, la recogida por Pellicer fue estudiada por Fuentes y Meijide (1979), destacando la presencia de conejo a lo largo de toda la secuencia, la presencia de carnívoros (lobo, zorro y lince) y entre los herbívoros se reconocen la cabra, el caballo, el ciervo y el rinoceronte (en la parte inferior de la secuencia, Estrato VIII). De esta colección destaca el sesgo que sufren los micromamíferos, lógicamente no recogidos sistemáticamente. Estas colecciones muestran una clara vinculación a ambientes del Pleistoceno Superior e incluso al Holoceno a partir del nivel VI (Vega 1988).

3.2.3.- Cueva del Boquete de Zafarraya (Alcauicín, Málaga): descubierto a comienzos de los años ' 80 , las intervenciones arqueológicas se han desarrollado en dos fases: una primera, durante los años 1981-1983, dirigida por C. Barroso, campañas que proporcionaron el mayor número de publicaciones que se conocen, hoy en día, sobre el yacimiento (Barroso et alii 1983; 1984; Medina et alii 1986; Barroso y Medina 1989). Una segunda fase comienza en 1989, con la creación de un importante grupo de investigadores (J. J. Hublin, P. Y. Demars, D. Geraads, J. Rodríguez-Vidal, etc... ), e instituciones avalando el proyecto (Diputación Provincial de Málaga, College de France, Universidad de Sevilla, de Granada, de París VI, Museo Nacional de Ciencias Naturales, ITGE, y un largo etc...). De esta segunda fase, las publicaciones brillan por su ausencia, conociéndose tan sólo las dataciones obtenidas en este período (Barroso y Hublin 1994; Hublin et alii 1995), y los informes pertinentes para la Junta de Andalucía, que son publicados todos los años en el Anuario Arqueológico de Andalucía. En la actualidad, las excavaciones están paralizadas desde el año 1994. 
Antes de comenzar a comentar los diferentes aspectos del yacimiento, queremos matizar que la investigación se encuentra pendiente de la publicación de una monografía, asíque los datos recientes son tan sólo informes preliminares (Barroso et alii. 1992; Barroso y Hublin 1994), por lo que también utilizaremos datos publicados de antiguo aunque algunos de ellos han sufrido modificaciones.

La estratigrafía del yacimiento se ha podido matizar en la segunda fase de excavaciones. Ya en los primeros momentos se dieron a conocer algunas notas sobre la génesis de la cavidad (Medina et alii 1986), pero el estudio sedimentológico de la cueva ha sido realizado por J. Rodríguez-Vidal y A. Caraballo en estos últimos años. De estos trabajos se deduce que se trata de un depósito que presenta una matriz arcillo-limosa que ha sido afectada por procesos de tipo químico y mecánico. El origen del registro es de procedencia autóctona, en el que la presencia de fragmentos rocosos es debida a fenómenos climáticos (crioclastia) y tectónicos (fracturas). El registro se caracteriza por ser un depósito de sedimentación continua, donde los únicos cambios que se aprecian se deben, fundamentalmente, a procesos postdeposicionales (cementaciones y coladas parietales). Resumiendo, los niveles estratigráficos que se han podido diferenciar partiendo de los procesos postdeposicionales, son los siguientes de muro a techo: la base de la secuencia está constituida por un material arcilloso, que se trata de la típica harina de falla, con ausencia total de rocas y totalmente estéril desde el punto de vista arqueológico; nivel arqueológico inferior con una potencia de un metro, está constituido básicamente por huesos, industria y fragmentos de roca fuertemente cementado por una colada de carbonatos; y nivel arqueológico superior, que presenta una potencia que varía de uno a dos metros dependiendo del lugar de la cueva, arqueológicamente presenta industria y fauna.

Respecto a los materiales del yacimiento, lo primero que hay que decir es que son sumamente interesantes y no estuvieron exentos de cierta problemática como más adelante veremos. A nivel paleontológico, llama la atención que más del $90 \%$ de la fauna de la cueva pertenezca a la misma especie, Capra Ibex Pyrenaica, hecho que en su día motivó la interpretación del lugar como un hábitat estacional de caza de esta especie. El resto de la colección la componen caballo, bóvido, rebeco, ciervo, jabalí, y entre los carnívoros se encuentran pantera, lince, gato salvaje, hiena, cuon, zorro y oso (Medina et alii 1986; Geraads, comunicación personal). En el yacimiento, igualmente se documenta una excelente colección de microfauna que está siendo estudiada y que, en su día, sirvió para situar cronológicamente la secuencia como más moderna que los registros de Carihuela. Igualmente, a partir de la microfauna se deducen algunos aspectos climáticos del depósito, como su pertenencia a una fase fría más que la actual y húmeda que, gradualmente, pasa a otra menos fría, pero que mantiene la humedad (Vega 1988).

La industria de Zafarraya se caracteriza, en primer lugar, por estar realizada en su práctica totalidad sobre sílex $(99,29 \%)$ presentando una gran homogeneidad en el tamaño de las piezas (Medina et alii 1986). Tecnológicamente, se considera una industria de debitage levallois no facetado (IF $40 \%$ y IFs $24,47 \%$ ). Tipológicamente, las raederas suponen un 20\% "en cuenta esencial" (Medina et alii 1986), el índice Charentiense es bajo (11,76\%), los denticulados están presentes con un índice discreto $(15,29 \%)$, las puntas presentan un porcentaje medio (3,52\%) y los útiles del Paleolítico Superior, tan sólo buriles y raspadores, se sitúan en un $4,70 \%$. Igualmente, en las publicaciones, tanto antiguas como recientes, se habla de una industria ósea que, tras más de diez años de su anuncio, sigue en estudio. Sin embargo, a toda esta serie de datos, algún autor (Vega 1988) ha presentado ciertos reparos como que: hay discrepancias entre los datos publicados en los diferentes artículos; imposibilidad de verificar datos porque no sabemos el número total de piezas encontradas, no está publicada la lista tipológica en su totalidad; y desconfianza en la aplicación de la técnica de análisis industrial (método Bordes), al menos en algunos elementos tecnológicos.

Recientemente se presentó un breve artículo en la reunión celebrada en Gibraltar, bajo el título "Gibraltar during the Quaternary" (Barroso y Hublin 1994). En esta publicación se señala que el estudio ha sido realizado por C. Barroso y F. Medina, en colaboración con A. Delagnes y los datos que se presentan son los siguientes: $41 \%$ de lascas producidas por técnica levallois (principalmente por el método centrípeto 
recurrente), el $17 \%$ son corticales y un $18 \%$ indiferenciadas, el $19 \%$ del conjunto está compuesto por fragmentos inclasificables y los núcleos representan un 2,5\%; tan sólo un 4,2\% de la serie lítica está retocada, encontrando entre los útiles, raederas, puntas musterienses, denticulados y muescas. En ningún momento se presentan los porcentajes de los distintos tipos, ni la lista tipológica, ni el número de piezas encontradas, presentando, en cierta medida, errores anteriores.

Respecto a las cronologías, Zafarraya cuenta con series de dataciones realizadas por los métodos del U/Th y del C 14, para las capas I y D, y que son las siguientes (Hublin et alii. 1995):

\begin{tabular}{|c|c|c|}
\hline NIVELES & U/TH & C 14 \\
\hline \multirow{2}{*}{ Capa I (3-7) } & $25.1 \pm 1.3$ & $29.8 \pm 0.6$ \\
\hline \multirow{2}{*}{ Capa I (8) } & $26.9 \pm 2.7$ & $31.8 \pm 0.55$ \\
\hline Capa D & $28.9 \pm 4.32$ & \\
\hline
\end{tabular}

3.2.4.- Cueva Ambrosio (Vélez-Blanco, Almería): yacimiento clásico del Sureste peninsular, conocido desde comienzos de siglo y por el que han pasado numerosos investigadores. La primera noticia procede de una carta que el erudito local, F. de Motos, dirige a su amigo Breuil en la que le indica que ha realizado unas trincheras en una cueva del lugar y que su relleno le parece Paleolítico. Más tarde, en 1912, Breuil, publicará una punta de muesca de la Cueva de Ambrosio y, en Abril de 1913, inicia excavaciones en el yacimiento, junto a Motos, cuyos resultados saldrán publicados en una breve nota de Breuil (Breuil y Obermaier 1913). El siguiente investigador que trabajará en la cueva será L. Siret. Sin embargo, esta afirmación es muy problemática y las noticias son bastante contradictorias (Paniagua, e. p.). Será a finales de los años "cincuenta" cuando se reanuden las excavaciones én el yacimiento, en este caso encabezadas por Eduardo Ripoll, y que se prolongarán hasta el año 1964 (Ripoll Perelló 1961). En 1975, un equipo del "Laboratorio de Antropología" de la Universidad de Granada, dirigido por M. Botella, reinicia las excavaciones en el yacimiento con las intenciones de ver si quedaba algún nivel intacto, proyectando una serie de sondeos, siendo lo más destacado el anuncio, en el Congreso Nacional de Arqueología de 1975, de un nivel auriñaciense debajo de la potente serie Solutrense. Por último, desde 1983 hasta nuestros días, se viene desarrollando un proyecto centrado en posicionar el yacimiento cronoestratigráficamènte, en el marco del Mediterráneo Occidental, destacando de estos trabajos el descubrimiento de arte parietal paleolítico en el abrigo, así como no haberse confirmado el Auriñaciense de M. Botella (Ripoll López 1988; Ripoll et alii. 1995, e.p.; Paniagua, e. p.).

La estratigrafía del yacimiento tiene una potencia de ocho metros, sin haberse alcanzado, en la actualidad, la roca madre. Se han podido diferenciar nueve niveles litoestratigráficos que, en líneas generales, y partiendo de la génesis de la secuencia, se pueden resumir en dos tramos: un primero que sería el nivel (1) de base, cuyo origen se debe a procesos de decantación de arcillas a la salida de la surgencia cárstica; y un segundo, que englobaría al resto de la secuencia, generada fundamentalmente por la caída de bloques debido a procesos de crioclastia y, en menor medida, a las acciones de la vegetación, como a los numerosos seísmos que se producen en la zona; dentro de este proceso habría momentos en que el clasticismo disminuiría, favoreciendo la arroyada difusa de las aguas procedentes de la visera como de la surgencia. Es precisamente en estas circunstancias cuando se produce la visita de grupos humanos a la cueva, en las que las condiciones climáticas mejoran, aumenta la humedad y la temperatura (Jordá Pardo y Carral 1988).

Respecto a los materiales, tiene una de las mejores colecciones solutrenses que se conocen. La inclusión de este yacimiento en el ámbito de la transición se debe a la problemática que originó M. Botella al anunciar 
en el Congreso Nacional de Arqueología de 1975 la existencia de un Auriñaciense bajo la potente serie solutrense. La verdad es que no se ha publicado nunca pero, de forma recurrente, se incluyen en las típicas síntesis regionales, como Fullola (1979, 1983), Cacho (1980), Fortea (1985, 1986), Fortea y Jordá (1976), Jordá (1986), Sanchidrián (1994), Vega (1993), siendo éste último uno de los que más confianza deposita en el excavador actual, ya que, como señala "sólo se han encontrado niveles estériles bajo las potentes capas solutrenses" (Vega 1993). En la actualidad, se ha presentado un trabajo encaminado a demostrar que las excavaciones de Botella nunca llegaron a la profundidad estratigráfica alcanzada por S. Ripoll; además, en una reciente revisión de los materiales procedentes de las campañas de Botella depositados en el Museo Provincial de Almería, hemos podido comprobar cómo no existen raspadores carenados, cómo tampoco aparecen las famosas azagayas (salvo un sólo fragmento distal, que no sobrepasa los $3 \mathrm{~cm}$ de longitud), además de aparecer en todas las bolsas de material algún elemento solutrense (Paniagua e. p.). Por último, el propio M. Botella, comunicó a S. Ripoll su precipitación a la hora de clasificar los materiales que encontró en su excavación como auriñacienses; igualmente, en las Jornadas Arqueológicas de Andalucía, celebradas en Córdoba en Diciembre de 1994, reconocía su error ante la pregunta de S. Ripoll sobre la existencia de Auriñaciense en este yacimiento.

3.2.5.- El Chorro (El Burgo, Málaga): yacimiento que se conoce desde finales de los años setenta, apareciendo en la bibliografía, bien como el taller de sílex del Chorro, o como El Chorrito. Realmente, consiste en un yacimiento en superficie, por lo que no disponemos de estratigrafía ni de dataciones absolutas, en el que no se ha excavado todavía pero que presenta una ingente cantidad de material lítico, el cual permitió hacer una aproximación cultural con las reservas que un yacimiento de este tipo lleva consigo. El único tipo de trabajo que se ha realizado ha sido una serie de recogidas de materiales en superficie, llevadas a cabo, fundamentalmente, por B. Ruiz González y J. A. Lèiva Riojano; con posterioridad a la finalización del único trabajo que existe sobre el yacimiento, J. L. Rodríguez (colaborador del Museo Arqueológico Provincial de Málaga) ofreció varias cajas de materiales procedentes del yacimiento que aún no han sido estudiadas (Ruiz y Leiva 1979).

De las recogidas superficiales únicamente se tienen restos líticos, sin comentarse nada sobre la existencia de restos óseos. Para el estudio del material lítico, se ha empleado la lista-tipo de Sonneville-Bordes y Perrot. El material consta de 2.150 restos líticos, de los que se han seleccionado 1.196 como típicos (el 55,62\% del total), que han sido los elementos analizados. Para las características y los índices de los diferentes grupos tipológicos, nos remitimos al trabajo de Ruiz y Leiva (1979) pero, analizando los índices disponibles, se puede observar que: raspadores y buriles tienen los mismos porcentajes; una elevada proporción de muescas y denticulados; preponderancia de los raspadores simples sobre carenados y en hocico; dominan los buriles diedros sobre los buriles con truncatura; elevado número de perforadores; ausencia total de utillaje geométrico y foliáceo y casi total de laminitas de dorso; presencia de los grupos auriñaciense y perigordiense, estando el primero de ellos representado por sus tipos más característicos, mientras que el segundo no presenta sus útiles más típicos (Ruiz y Leiva 1979).

Para los autores, la disparidad de los datos se explicaría por "la sucesiva reutilización del taller por grupos culturales diferentes" (Ruiz y Leiva 1979). A pesar de esta disparidad, y a espera de realizar un sondeo estratigráfico que confirme la larga ocupación del yacimiento, estos investigadores destacan las siguientes características: relación entre buriles y raspadores, próxima a la unidad; elevado número de muescas y denticulados que forman parte de los elementos del substrato; dominio de los raspadores simples y de los buriles diedros; grupo Auriñaciense bastante completo. Finalmente, el conjunto lítico podría encajar perfectamente en un Auriñaciense Evolucionado (Ruiz y Leiva 1979). 
Por último desde nuestra perspectiva, tanto el análisis de materiales como su interpretación carecen de valor ya que se trata de una selección de materiales procedentes de una no menos selecta recogida superficial, con todos los problemas que ello conlleva.

3.2.6.- El Bajondillo (Torremolinos, Málaga): localizado en 1989 en la labor de Vigilancia Arqueológica de unas edificaciones, los trabajos de excavación fueron llevados a cabo por el Área de Prehistoria de la Universidad de Málaga, siendo publicadas únicamente sucintas noticias (Baldomero et alii. 1989-90, 1991; Marques y Ferrer 1991). El estado de la investigación de los materiales es, en la actualidad, de estudio, por lo que tan sólo contamos con datos provisionales presentados en las reuniones de Bañolas de 1995 y de Nerja de 1996. Por último, queremos aclarar que no se trata de la misma Cueva del Bajondillo que se encontró en la zona de Torremolinos con una importante colección de materiales neolíticos.

La estratigrafía del yacimiento proviene de una parte de relleno que fue salvada en las labores de seguimiento. Este relleno se situaba próximo al farallón rocoso, mostraba una superficie triangular y una potencia máxima de 5,20 m Sobre este retazo de depósito, se plantearon dos sondeos. El primero fue impracticable debido a la presencia de grandes bloques de travertino que impidieron su excavación. Un segundo corte, sin embargo, permitió la documentación de toda la secuencia estratigráfica. Los estudios sedimentológicos están en curso, pero se documentan en algunos estratos cantos de travertino de procedencia gravitacional, episodios de brechificación, matriz casi arenosa (probable aporte de baja energía) e inexistencia de alteraciones en el material arqueológico. Igualmente, se registran procesos postdeposicionales que alteran, en algunos tramos, la correcta lectura de la serie. Se han diferenciado 17 estratos, sin matizarse el motivo de diferenciación, de los cuales los cinco primeros son estériles, el intervalo 6-8 se corresponde con los restos solutreogravetienses, el estrato 9 es Solutrense Medio, el 10 es Gravetiense, el 11 Auriñaciense y del 12 al 17 son series musterienses. Impresionante coincidencia de los diferentes estratos con los diferentes momentos culturales representados en la secuencia, hasta el punto de plantearnos si se trata realmente de una estratigrafía geológica o cultural. Respecto a esta "interesante" estratigrafía, queremos reproducir un texto de la primera publicación (en referencia a la secuencia solutreogravetiense) que se realizó sobre el yacimiento: "Representan estos materiales, como expondremos más adelante, la fase intermedia de la secuencia estratigráfica recuperada, correspondiendo el substrato anterior a una ocupación musteriense, y el posterior a un momento bien Neolítico Final, bien transicional al Cobre, cuya duda se plantea por una cierta indefinición de sus materiales, insuficientes por otro lado para la necesaria precisión" (Marques y Ferrer 1991).

En el estrato 11 se destaca la presencia de unos materiales que han sido encuadrados como pertenecientes a un Auriñaciense. No tenemos porcentajes, ni tipológicos, ni tecnológicos aún, pero en el escueto conjunto lítico se destacan las laminitas con retoque marginal simple (algunas, incluso, pueden ser laminitas Dufour), raspadores en hocico, espesos, y sobre lámina retocada, buriles (en mayor presencia que los raspadores) diedros y sobre truncatura. No hay industria ósea que permita atribuir con más precisión este conjunto a un momento determinado del Auriñaciense. Respecto al material paleontológico, no se ha comentado nada, tan sólo la presencia de restos óseos en algunos niveles. En la primera publicación (Marques y Ferrer 1991), no se habla de fauna, ni se presentan índices tecnotipológicos, ni existe un recuento de material, etc... Se destaca el componente laminar del conjunto y el "alto grado de depuración técnica en su elaboración", además de los distintos tipos documentados: puntas de muesca, laminitas de dorso abatido, raspadores sobre lámina, buriles sobre fractura y sobre truncatura, geométricos y útiles con muescas. Estos datos llevaron a los autores a encuadrar estos materiales en un Solutreogravetiense.

En el terreno cronológico, no se dispone de dataciones absolutas para el yacimiento, pero los estudios sedimentológicos, polínicos y bioestratigráficos permitirán hacer una aproximación a su encuadre cronoestratigráfico dentro del Pleistoceno Superior. Recientemente, en una publicación sobre el Paleolítico andaluz, en un cuadro cronoestratigráfico del Pleistoceno Superior, la secuencia del yacimiento de El Bajondillo 
comenzaría en un momento próximo al final del Würm I (o fase isotópica 5a) y continuaría sin interrupción hasta ver su final en momentos correspondientes a los comienzos del Dryas Ib (Cortés et alii 1996). Es muy importante señalar que en ningún momento se han explicado los motivos de la ubicación de los diferentes estratos en tal o cual momento paleoclimático.

Para finalizar, queremos señalar que existe una gran contradicción entre lo que se publicó en 1991 (Marques y Ferrer) y lo que se ha presentado en el Congreso de Bañolas (1995) y en el Simposio de Nerja (1996). No nos resulta coherente el hecho de que, en un principio, se presentara el paquete central de la estratigrafía (por debajo Musteriense, por encima Postpaleolítico) como Solutreogravetiense y que en las reuniones mencionadas más arriba, ese paquete se haya transformado en tres niveles solutreogravetienses, uno Solutrense Medio, otro Gravetiense y otro Auriñaciense, es decir, toda la secuencia clásica del Paleolítico Superior. Esta transformación de la estratigrafía en cuestión de cuatro años, sin ninguna nueva intervención, sumado a la ausencia de datos fundamentales como la sedimentología, el estudio arqueozoológico de los restos óseos, la carencia de dataciones, etc... y que se trata de un lugar en obras que cuando llegaron los arqueólogos ya encontraron piezas en superficie, nos hace dudar de la valoración que se ha hecho del yacimiento dadas las evidencias que existen en la actualidad.

3.2.7.- Cueva de Nerja (Maro, Málaga): descubierta en 1959, las investigaciones fueron iniciadas por M. Pellicer, quien puso de manifiesto los restos prehistóricos de la cueva, su importancia para el Mediterráneo Occidental y los contenidos culturales, estableciendo la primera secuencia: Epipaleolítico, Neolítico y Calcolítico. En 1962, A. M ${ }^{\text {a }}$ de la Quadra Salcedo realizó un sondeo en la Sala del Vestíbulo, aumentando la secuencia cultural que se conocía de la cueva al documentar el Paleolítico Superior. En 1965, F. Jordá Cerdá es invitado por el Patronato de la Cueva de Nerja para realizar investigaciones en la Sala de la Mina. Estos trabajos se prolongaron hasta 1968, centrándose el interés de Jordá en los niveles Paleolíticos, por lo que para trabajar los restos postpaleolíticos se asoció a A. Arribas. De estos trabajos, los investigadores mencionados realizaron una monografía, que nunca vio la luz por causas ajenas a ellos (Jordá 1986). Más tarde, en los años "ochenta", se iniciará un nuevo proyecto de excavación bajo la dirección de M. Pellicer y F. Jordá.

Los trabajos llevados a cabo en la cueva se han centrado en dos áreas principales: la Sala de la Mina y la Sala del Vestíbulo. Ambas salas están parcialmente rellenas de sedimento, responsable directo del cierre de las bocas que daban acceso a estos espacios. Estos depósitos se disponen más o menos paralelos al suelo de la cueva, con un ligero buzamiento hacia el NW. Tienen una potencia variable que oscila entre los $6 \mathrm{~m}$ de la Sala de la Torca y los $3 \mathrm{~m}$ de la Sala del Vestíbulo. Debe tenerse en cuenta que los depósitos que rellenan las salas son diferentes a los que cierran las bocas de acceso y las relaciones entre ellos no están claras de momento. La estratigrafía de la cueva es provisional a falta de que se puedan terminar los trabajos. Por lo que se refiere a la paleoclimatología que se puede inferir a raíz del análisis de la estratigrafía y, por comparación con otras zonas como el cantábrico y el área mediterránea (Hoyos 1980; Fumanal 1985), los primeros depósitos de Nerja se acumularían bajo un clima de características húmedas y ligeramente frías, que se corresponden con las ocupaciones auriñacienses y, por comparación con otras zonas, quizá se trate de las últimas etapas del Würm III. La sedimentación prosigue en el Vestíbulo, mientras que en la Mina se produce la gran "cicatriz" erosiva. Estos niveles pueden situarse en el final del Würm III o en el interestadio Würm III-IV, correspondiendo las etapas erosivas al Würm III-IV o al Würm IV. A continuación, nos encontramos con los niveles de plaquetas que, sin duda alguna, nos indican un momento frío, que puede ser el Würm IV. Tras esta etapa fría, nos encontramos ante un momento templado y húmedo, que correspondería al final del Würm IV. A partir de este momento, se desarrollan los períodos postpaleolíticos del yacimiento, con lo que paleoclimáticamente todo pertenece al Holoceno (Jordá Pardo 1986).

A lo largo de la secuencia de la Cueva de Nerja se registran distintas ocupaciones que corresponden a diferentes momentos culturales del pasado del hombre. Estos momentos son: Paleolítico Superior Inicial 
(Auriñaciense para los excavadores), Solutrense, Magdaleniense, Neolítico y Calcolítico. El yacimiento ha sido incluido en nuestra síntesis por la existencia de ese Auriñaciense. Por lo tanto, nos centraremos única y exclusivamente en el análisis de esos materiales, olvidando el resto de la secuencia que carece de interés para nosotros en estos momentos.

Los restos paleontológicos de la cueva fueron estudiados por diferentes especialistas. Así, los mamíferos fueron analizados por M. Pérez Ripoll (1986). Recientemente, ha salido a la luz una monografía centrada en fauna, procedente de las campañas de 1980-82, en la cual no se incluye el estudio definitivo de los mamíferos encontrados en los niveles Paleolíticos, por lo que sólo contamos con el informe preliminar de 1986. Los restos son verdaderamente escasos y en ellos destaca el conejo, acompañado de 6 restos de cabra, dos de ciervo, dos restos de roedores, y uno de ave (Pérez Ripoll 1986). La escasez de restos anula cualquier intento de conjetura.

Respecto a los restos líticos, la escasez también hace acto de presencia. Los restos proceden de los niveles 17, 18 y 19 de la Sala de la Mina y del 11, 12 y 13 de la Sala del Vestíbulo, siendo ésta última, en el corte denominado C-4, la que ofreció los restos más interesantes, que consistían en dos raspadores sobre hoja, un raspador-buril, un buril de ángulo, una pieza con retoque abrupto y 3 piezas denticuladas. F. Jordá Cerdá considera que los rasgos apreciables en las piezas son insuficientes para tomar una decisión pero, por la presencia de la pieza con retoque abrupto, opina que debe ser un momento avanzado dentro de los inicios del Paleolítico Superior, ya con influencias gravetienses. Sin embargo, los raspadores y buriles se le hacen muy antiguos, con lo que se inclina por un Auriñaciense sensu lato (Jordá 1986).

En el reciente Simposio de Prehistoria Cueva de Nerja se presentó una comunicación referente a la ocupación más antigua de la cueva, expuesta por E. Aura, que había realizado una revisión del material procedente de los niveles anteriormente comentados. La conclusión era que el material es escaso, apenas una quincena de piezas, por lo que era difícil inclinarse por un período u otro, pero sí remarcó que de ser algo, se aproxima más a un Gravetiense que a un Auriñaciense.

Referente a la cronología, no se puede decir nada, ya que estos niveles no fueron datados. Tan sólo partiendo de los estudios sedimentarios, estos niveles podrían corresponder, como se ha dicho antes, a las etapas finales del Würm III.

\subsection{8.- Gibraltar}

Los yacimientos de Gibraltar son numerosos. Entre ellos se encuentran Genista, Forbe's Quarry, St. Michael's Cave, Leonora's Cave, Devil's Tower, Gorham's Cave y otros inéditos conocidos recientemente, como Vanguard's Cave e Ibex's Cave. A continuación, veremos rápidamente los yacimientos de Devil's Tower y Gorham"s Cave.

Devil's Tower: yacimiento próximo a la cantera de Forbe, fue dado a conocer por el abate Breuil, quien ya señaló la presencia de una serie de hogares y niveles de hábitat con industria musteriense, todo ello muy cementado. El análisis de los restos faunísticos, realizado por M. Harlé y entre los que destacaba la elevada presencia de carnívoros, propició que Breuil interpretara la cueva como un cubil de carnívoros, siendo éstos los principales artífices de la acumulación ósea y quedando el papel del hombre reducido a visitas esporádicas (Breuil 1922; Vega 1993).

Más tarde será D. A. E. Garrod quien realice trabajos en el sitio, producto de los cuales son los primeros dibujos y fotografías del yacimiento, así como el primer estudio estratigráfico (Garrod 1928). El depósito fue dividido en tres unidades principales, sin establecerse diferencias microestratigráficas ni análisis sedimentológicos precisos. La primera unidad está constituida por una playa levantada, la segunda unidad es una sucesión de seis niveles de arenas eólicas que alternan con formaciones travertínicas y tobáceas muy cementadas, serie donde se encontraron los restos arqueológicos y, por último, la tercera unidad respondía 
a un depósito de ladera que fosilizaba el conjunto anterior. Parece ser que, tras la formación de la última unidad, algunos procesos de erosión se tuvieron que dar, ya que el contacto de los niveles cementados es abrupto y escalonado, muy discordante con la vertiente moderna (Vega 1993).

Los materiales de la cueva no han vuelto a ser repasados desde la publicación de la monografía de Garrod. La colección faunística fue estudiada por D. M. A. Bate (1928) y, entre la larga lista de especies, se encuentran el lobo, el oso pardo, la hiena, el lince, el gato montés, el conejo, el jabalí, el ciervo, los bóvidos, la cabra, el caballo y el elefante, además de una larga lista de microfauna y aves. De este estudio, destaca la confirmación del planteamiento realizado por Breuil años antes (que hacía alusión a su uso como cubil de depredadores). Respecto a la industria, los datos de que disponemos se remontan a los dibujos de la publicación de Garrod; según se desprende de ésta, se trataría de un Musteriense Típico ya que no presenta bifaces, ni raederas tipo quina, además, las raederas presentes son variadas, hay puntas musterienses, se pueden observar núcleos discoides con preparación periférica y lascas levallois (Garrod 1928; Vega 1988). Estas aproximaciones han sido confirmadas recientemente en el estudio que ha realizado C. M. Barton (1988).

Por lo que respecta a la cronología del depósito, Garrod lo sitúo en el Pleniglaciar Inferior Würmiense, ya que la playa del nivel 7 , primera unidad estratigráfica comentada con anterioridad, representaría el episodio transgresivo Monastiriense del último Interglacial. Años más tarde, una muestra procedente del nivel 3, perteneciente a la segunda unidad estratigráfica, fue analizada por el método del C14, que arrojó una cronología de 30.000 años, que no representa mucho a la hora de detallar los eventos sucedidos en la importante secuencia del yacimiento.

Gorham's Cave: yacimiento que reactivó la investigación en Gibraltar a mediados de siglo, con un proyecto muy ambicioso para su tiempo. Estos trabajos fueron dirigidos por J. d'A Waechter en colaboración con F. Zeuner y pretendían realizar análisis crono-sedimentarios, paleontológicos y arqueológicos, con la finalidad de correlacionar los resultados obtenidos con los conocidos para ver la evolución del Pleistoceno Medio y Superior en el Mediterráneo Occidental. En la actualidad, los trabajos se han reiniciado bajo la dirección de la Dra. Cook y el Dr. C. Finlayson, en colaboración con el Grupo Andaluz de Cuaternario.

Los procesos de sedimentación y los cambios climáticos han sido recientemente publicados (Díaz del Olmo 1994), partiendo de la secuencia más externa del interior de la caverna, es decir, la que está situada en la pared Norte. En líneas generales, se pueden diferenciar tres unidades en la potente y heterogénea secuencia: la inferior, como gres de playa; la intermedia, de carácter detrítico; y la superior, que alterna brechas y fases de carbonatación del carst. Resumiendo, las características sedimentológicas del registro "muestran una secuencia sedimento-climática, polifásica, con imbricación de procesos marinos, eólicos y continentales, éstos últimos principalmente de carácter detrítico (brechas) y geoquímico (espeleotemas). El marco geocronológico de los cambios climáticos remite, en lo fundamental, al estadio isotópico 5 (ca. 130.000-74.000 años BP), con mantenimiento de las condiciones en el Tardiglaciar (ca. 18.000-14.000 años BP)" (Díaz del Olmo 1994).

La lista faunística del yacimiento fue determinada por Zeuner y Sutcliffe (1964) en lo referente a la macrofauna, en la que se observan el lobo, el oso pardo, la hiena, el gato salvaje, dos especies de pantera, el rinoceronte, el jabalí, el ciervo, los bóvidos, la cabra, el conejo, la foca gris, además de un listado que supera las cuarenta especies de aves, que fueron estudiadas por Easthan (1967). Del conjunto faunístico de Gorham destaca: la elevada presencia de carnívoros a lo largo de toda la secuencia; los herbívoros documentados representan el medio circundante, así como los patrones cinegéticos de los depredadores de la cueva; en el plano ecológico, Gorham presenta claros marcadores de un clima más frío que el actual, (por ejemplo la foca gris, típica del Atlántico Norte, que rara vez sobrepasa el Canal de la Mancha); por último, y teniendo en cuenta la secuencia de Devil's Tower, los investigadores ingleses destacan la total ausencia de fauna africana en el área. 
Para comentar la industria, seguiremos la estratigrafía que estableció Waechter, el cual subdividió la secuencia en dieciocho niveles. De estos dieciocho niveles, cuatro destacaban por su clara adscripción musteriense, otros dos por su aspecto de Paleolítico Superior (uno de ellos, el que se dio y se mantiene como Auriñaciense) y los dos últimos, a techo de la secuencia, postpaleolíticos, estando el superior totalmente revuelto; además, en otros niveles, se ha encontrado alguna pieza que se interpreta como derivaciones de niveles superiores ricos en material. De los niveles de Paleolítico Superior (niveles D y F) destaca el D en el que se encontraron raspadores sobre lasca, buriles diedros y sobre truncatura y hojas de dorso, pero no apareció industria ósea característica. En el $\mathrm{F}$ se halló una industria poco clara que presentaba raspadores sobre lasca y nucleiformes y un fragmento de azagaya (Vega 1988), nivel éste que se corresponde con el Auriñaciense, muchas veces citado, de Gorham. De los niveles con restos de industria musteriense destacan el G, el K y el M. Estas industrias se caracterizan por no presentar bifaces ni raederas tipo quina, aunque gran parte del resto de tipos sí están representados, como puntas musterienses, algunos denticulados, raspadores y buriles. Tecnológicamente, hay una elevada presencia de núcleos discoides agotados, así como numerosas hojas de buen tamaño (Waetcher 1951, 1953, 1964; Vega 1988).

La cronología que se propuso para el conjunto de la estratigrafía se apoyaba en el estudio sedimentológico realizado por Zeuner (1953), proponiéndose un esquema similar al de Devil's Tower, es decir, playa monastiriense en la base, sobre la que se apoya toda la secuencia de ocupaciones musterienses y, sobre ésta, se documentaban niveles postmusterienses y holocenos (Vega 1988). Pero toda esta cronoestratigrafía fue deshecha debido a la aplicación`del método del C14 a los niveles D y G, que ofrecieron una cronología de 28.000 años para el primero y de 47.500 años para el segundo.

\section{LOS PLANTEAMIENTOS}

La investigación en Andalucía es muy precoz, ya que de finales del siglo pasado proceden los primeros estudios, como ya vimos en paginas anteriores. Es de estos mómentos la primera seriación del Paleolítico andaluz que corre a cargo de L. Siret y en ella matiza que el registro del Paleolítico en Andalucía es semejante al de la zona clásica francesa, viéndose en las diferentes estratigrafías un rico Musteriense, al que le sucede toda la secuencia del Paleolítico Superior (Siret 1893, 1933).

Pero los primeros apuntes interesantes para el problema de la transición fueron aportados por Waechter tras sus trabajos en Gibraltar. Apoyándose en los estudios sedimentológicos de la cueva de Gorham, realizados por Zeuner, correlacionó los episodios húmedos de la cueva con los episodios interestadiales de la Europa continental observando, de esta forma, que el Musteriense del nivel G de Gorham era contemporáneo del Auriñaciense francés y, por lo tanto, que los neandertales del Sur de la Península perduraron más que en el resto del continente. Posteriormente, los intentos de continuar la secuencia fueron abandonados cuando las fechas radiocarbónicas obtenidas para los niveles D (Paleolítico Superior) y G (Musteriense) anularon la cronoestratigrafía establecida por medios geológicos (Waechter 1964).

Para el área del Sureste peninsular se cuenta con los trabajos de C. Cacho $(1979,1980,1982)$. Esta autora estableció la secuencia cultural del Sureste, a través de la revisión de los materiales de la colección Siret, acompañada de la prospección de algunas áreas de la zona y de algunas intervenciones arqueológicas, como la realizada en Vermeja en 1977. Antes de centrarse en la problemática del Paleolítico Superior, dedica unas líneas al tema de la transición desde el Paleolítico Medio, partiendo de yacimientos como Palomarico, Perneras, Vermeja y Zájara I, que presentan en su secuencia niveles musterienses seguidos de Paleolítico Superior. Si en estos yacimientos existía algún nivel transicional (como podría ser el nivel medio de Palomarico, considerado como revuelto, o el nivel 1 de Zájara I, índice laminar muy elevado con muchos denticulados), éste se ha perdido debido a lo rudimentario de las técnicas de excavación empleadas por Siret, o los investigadores 
recientes no han visto elementos distintivos para establecer su diferenciación. Por lo tanto, para esta autora "después del Musteriense existe en el Sureste un gran vacío cultural hasta el Perigordiense Superior, con la excepción de algunos escasos restos auriñacienses. Este vacío es posible que se deba a una larga perduración del Musteriense en la zona,..., pero puede también deberse a una fase de fuerte erosión que eliminase los depósitos acumulados a lo largo del Würm III" (Cacho 1980). Respecto a la secuencia de los comienzos del Paleolítico Superior en la región, no reconoce ningún nivel perteneciente al Chatelperroniense pero sí identifica el Auriñaciense (del que matiza que "es la cultura peor conocida en la región") y el Perigordiense Superior, "que se presenta con unas características locales bien definidas" (Cacho 1980).

F. J. Fortea, en su artículo "El Paleolítico Superior y Epipaleolítico en Andalucía. Estado de la cuestión cincuenta años después" (1986), es partidario de la no existencia de industrias paralelizables al Chatelperroniense francés en el Sur de la Península, al igual que no le convence la hipótesis del mustero-auriñaciense que empezaba a rebatirse en otras áreas levantinas. Sin embargo, la existencia de Auriñaciense, desde Cataluña hasta Gibraltar, y su presencia constatada a través de "dos potentes series" en el yacimiento almeriense de Cueva de Ambrosio, motiva al autor a pensar que los comienzos del Paleolítico Superior en Andalucía "se organizan a partir del Auriñaciense Típico". Respecto a la seriación del Paleolítico Superior Inicial en Andalucía, para Fortea, como hemos dicho, comenzaría con el Auriñaciense y le seguiría el Gravetiense, aunque muy mal conocido.

Para G. Vega Toscano, el problema de la transición del Musteriense al Paleolítico Superior en el sector meridional de la Península Ibérica supone una cuestión fascinante. El autor se inclina por una convivencia de ambos tipos raciales en algún momento del Würm III: la fuerte presión sobre los recursos llevaría a las poblaciones del Paleolítico Superior a desarrollar un comportamiento más competitivo mediante la creación de nuevos sistemas de interacción social e intergrupal, en los que los neandertales quedarían fuera, provocando logicamente su extinción. Para este investigador, ésta parece la única explicación posible para la extinción de los neandertales, "por muy racista o catastrofista que parezca" (Vega 1988).

Para finalizar, el planteamiento de Vega, respecto a los comienzos del Paleolítico Superior, es: "en el sureste español y Andalucía Oriental sólo existen pruebas dudosas de un Auriñaciense posiblemente avanzado (Nerja, tal vez, Ambrosio), mientras que las ocupaciones Gravetienses parecen no estar tampoco muy bien representadas; la primera industria del Paleolítico Superior que parece contar con evidencias numerosas es el Solutrense, aunque en casi ningún caso presentan estratigrafías largas que permitan formular seriaciones respecto a industrias anteriores. Este resultado confirma la viabilidad de nuestra secuencia con los datos disponibles sobre el Paleolítico Superior Inicial y plantea un interesante problema histórico respecto a la necesaria convivencia entre ambos tipos humanos en algún momento del Würm III y la falta de transformaciones instrumentales dentro de las poblaciones neandertalenses, puesto que si hay algo que todavía permanezca inmutable es la ausencia de algún tipo de auriñacomusteriense" (Vega 1993).

En el reciente Simposio de Nerja salió a luz un volumen monográfico sobre el Paleolítico en Andalucía (Cortés et alii 1996), en el que se hacía un rápido repaso al estado de la cuestión de los diferentes períodos. No analizan el tránsito de los "tecnocomplejos musterienses" al Paleolítico Superior Inicial, pero sí realizan una seriación de éste último. Como primera medida, avisan de que las citas de Auriñaciense provienen, en su mayoría, de excavaciones antiguas y que de la perduración de los neandertales "se ha pasado de la pervivencia a la convivencia con el hombre anatómicamente moderno" (Cortés et alii 1996). Entre los yacimientos con Auriñaciense citan Cueva Horá y El Chorro como problemáticos o, más bien, que tienen ese tal Auriñaciense citado con anterioridad; de Nerja y Gorham's Cave aceptan su Auriñaciense sensu lato sin más, nuevamente incluyen Cueva Ambrosio como yacimiento que presenta Auriñaciense y, por último, presentan Cueva del Bajondillo como el gran yacimiento andaluz que contiene el Paleolítico Superior Inicial (recordemos Auriñaciense en el estrato 11 y Gravetiense en el estrato 10) y que, junto a Nerja, resolverá los problemas de este período. A continuación, se desarrollaría un Gravetiense, presente en Zájara II, Bajondillo 
y Nerja (que tan sólo tiene un nivel por debajo del Solutrense y que, con anterioridad, fue situado en el Auriñaciense), y seguidamente, se desarrollaría el Solutrense y el Magdaleniense.

Para los responsables de la excavación de Zafarraya, el lugar muestra nuevos puntos de vista sobre el proceso de reemplazamiento de los neandertales por poblaciones de hombres modernos. Así con las recientes dataciones de Zafarraya (aunque matizan que deben ser confirmadas por otros sitios), piensan que la coexistencia de ambas poblaciones en la Península Ibérica debió de ser muy larga, de al menos 10.000 años. Esto rompería el concepto de una sustitución rápida y brutal de un grupo por otro, lo cual llevaría a una complicación del escenario del Oeste europeo en el proceso de poblamiento por parte del hombre moderno (Barroso y Hublin 1994; Hublin 1996).

J. Ramos, en un reciente trabajo sobre el Paleolítico Superior en la Bahía de Málaga, piensa en una zona de refugio para los neandertales y en la cohabitación de éstos, en sus últimos momentos, con los hombres modernos, planteándose "al menos conceptualmente interesantes problemas sobre convivencia, aculturación, enculturación, relaciones de dependencia". Respecto al Paleolítico Superior entiende "la aculturación y la innovación propias como modelos de explicación de las primeras industrias del Paleolítico Superior, sobre bases propias tecnológicas del mundo musteriense". De esta forma piensa que la secuencia goza de una fuerte personalidad, que hace cuestionar el esquema clásico francés en el Sur peninsular por lo menos hasta el Solutrense (Ramos 1994).

\section{CONCLUSIONES}

Visto el registro arqueológico del Sur de la Península Ibérica y los planteamientos de los diferentes autores sobre el problema de la transición, queremos exponer nuestra opinión:

1.- Es indudable que nos encontramos ante los neandertales más modernos de Europa, como parecen indicar las secuencias de Gorham Cave, Devil Tower, Cueva de Carihuela y Zafarraya, yacimientos donde los complejos musterienses, acompañados en algunos casos de restos fósiles de sus autores, parecen mantenerse hasta bien avanzado el Würm III.

2.- Pensamos que con base en los datos que se manejan en la actualidad, la convivencia entre neandertales y hombres modernos no es clara, ya que las fases iniciales del Paleolítico Superior en la región son dudosas o no están presentes, con lo que carecemos de su posicionamiento cronoestratigráfico para poderlo contrastar con las fases finales de los complejos musterienses. Además, están carentes las interestratificaciones.

3.- Si la convivencia no es evidente, creemos que lo es aún menos la extinción de los neandertales. Hasta el momento, la única hipótesis al respecto es la realizada por Vega, pero ésta pasa por una convivencia entre ambos tipos raciales. Igualmente, una transición amortiguada por un complejo transicional (del tipo Chatelperroniense como se documenta en la región cantábrica o en el Suroeste francés) es inviable por los mismos motivos, además de la ausencia de este tipo de respuestas adaptativas, por parte de los neandertales, en el Sur peninsular. Igualmente estos motivos hacen difícil pensar en un Paleolítico Superior con raíces musterienses.

4.- Para finalizar, señalar el claro desconocimiento de la evolución seguida por el Paleolítico Superior en la zona, donde cada vez aparece como más evidente que fue durante los momentos solutrenses cuando se produce un auténtico poblamiento por parte de los hombres anatómicamente modernos, de todo el Sur de la Península Ibérica. 


\section{6.- BIBLIOGRAFÍA}

ALMAGRO, M.; FRYXELL, R.; IRWIN, H. T. y SERNA, Ma D. (1970) "Avance a la investigación arqueológica, geocronológica y ecológica de la Cueva de la Cariguiela (Piñar, Granada)". Trabajos de Prehistoria 27, pp. 45-48.

AYARZAGUENA, M. (1991) "Historiografía española referida a la Edad de Piedra desde 1868 hasta 1880". Historiografía de la Arqueología y de la Historia Antigua en España (Siglos XVIII-XX), pp. 69-72.

BALDOMERO, A., MARQUES, I. y FERRER, E. (1989-90) “Intervención de urgencia en el Bajondillo (Torremolinos, Málaga)". Mainake XI-XII, pp. 11-20.

BARROSO, C., GARCÍA-SÁNCHEZ, M., RUIZ-BUSTOS, A., MEDINA, M. y SANCHIDRIÁN, J. L. (1983) "Avance al estudio cultural, antropológico y paleoecológico de la cueva del "Boquete de Zafarraya" (Alcaucín, Málaga)". Antropología y Paleoecología Humana 3, pp. 3-7.

BARROSO, C., MEDINA, M., SANCHIDRIÁN, J. L., RUIZ-BUSTOS, A., y GARCÍA-SÁNCHEZ, M. (1984) "Le Gisement mousterien de la grotte du Boquete de Zafarraya (Alcaucín, Andalousie)". L'Anthgrpologie, 88, pp. 133-134.

BARROSO, C. y MEDINA, M., (1989) "El último neandertal”. Investigación y Ciencia, 153, pp. 37-39.

BARROSO, C., HUBLIN, J. J. y MEDINA, F. (1992) "Zafarraya y el reemplazamiento de los Neandertales por el Hombre Moderno" en Investigaciones Arqueológicas en Andalucía (1985-1992), Proyectos, pp. 229-238.

BARROSO, C. y HUBLIN, J. J. (1994) "The late Nenderthal site of Zafarraya (Andalucía, Spain)" en "Gibraltar during the Quaternary", Rodríguez, F. Díaz del Olmo, F., Finlayson, C. Giles, F. (Eds.), AEQUA monografías, 2, pp. 61-70.

BARTON, C. M. (1988) "Lithic variability and middle paleolithic behaviour: new evidence from the Iberian Peninsule". BAR International Series, 408, pags. 129. Oxford.

BATE, D. M. A. (1928) "The Animal Remains of Devil's Tower, Gibraltar". Journal of the Royal Anthropological Institute of Great Britain and Ireland, LVIII, pp. 57-91.

BOTELLA, M. y MARTÍNEZ, C. (1979) "Estudio de las campañas 1977 y 1978 en Cueva Horá". Antropología y Paleoecología Humana, 1, pp. 59-74.

BOTELLA, M., MARTÍNEZ, C., CÁRDENAS, F. J. y CAÑABATE, M. J. (1983) “Las industrias paleolíticas de Cueva Horá (Darro, Granada): avance al estudio técnico y tipológico”. Antropología y Paleoecología Humana, 3, pp. 13-48.

BOTELLA, M., MARTÍNEZ, C., CÁRDENAS, F. J. (1986) "Industria musteriense y achelense en Cueva Horá (Darro, Granada)" en Homenaje a Luis Siret, pp. 79-83. Sevilla.

BREUIL, H. (1913) "Les subdivisions du Paleolithique superieur et leur Signification" en Actas Congrès Préhistorique de France, 14 sesión, pp. 165-238. Ginebra (1912).

BREUIL, H. (1922) "Palaeolithic man at Gibraltar: New and Old facts". Journal of Royal Anthropological Institute of Great Britain and Ireland, LI, pp. 46-54.

BREUIL, H. y OBERMAIER, H. (1913) “Institut de Paleontologie Humaine, travaux executes en 1912”. L'Anthropologie, 24, pp. 333-341.

CABRERA, V. (1996) "Del Musteriense al Paleolítico". Gallaecia, 18, pp. 123-130.

CABRERA, V. y BISCHOFF, J. L. (1989).- "Accelerator 14C dates for Early Upper Paleolithic (Basal Aurignacian) at El Castillo Cave”. Journal of Archaeological Science, 16, pp. 577-584.

CABRERA, V. y BERNALDO DE QUIRÓS, F. (1990).- "Donnes sur la transition entre le Paleolithique Moyen et le Superieur a la región Cantabrique: revision critique" en "Paléolithique moyen récent et Paléolithique supérieur ancien en Europe. Ruptures et transitions: examen critique des documents archéologiques". Actes du Colloque international de Nemours, Farizy, C. (ed.), Mémoires du Musée de Préhistoire d'Ile de France, 3, pp. 185-188. París. 
CABRERA, V. y BERNALDO DEQUIRÓS, F. (1993).- "L'Aurignacien de la región cantabrique espagnole" en Actes du XIIe Congrès International des Sciences Préhistoriques et Protohistoriques, 2, Institut Archéologique de l'Académie Slovaque des Sciences, pp.173-181, Bratislava (1991).

CABRERA, V. y BERNALDO DEQUIRÓS, F. (1996).- "The origins of the Upper Palaeolithic: a cantabrian perspective" en "The last neandertals the first anatomically modern humans: A tale about the human diversity. Cultural Change and Human evolution: the crisis at $40 \mathrm{ky}$ BP", Carbonell, E. y Vaquero, M. (ed.), pp. 251-265. Barcelona.

CACHO, C. (1979).- El Paleolítico Superior en el Sureste de la Península Ibérica. Tesis Doctoral, Universidad Complutense, 2 vol., pags. 939. Madrid.

CACHO, C. (1980).- "Secuencia cultural del Paleolítico Superior en el Sureste español". Trabajos de Prehistoria, 37, pp. 65-108.

CACHO, C. (1982).- "El Paleolítico Superior del Levante español en su contexto del Mediterráneo occidental (S. E. de Francia e Italia)". Itálica. Cuadernos de Trabajo de la Escuela española de $H^{a}$ y Arqueología en Roma, 16, pp. 7-32.

CANN, R. (1988).- "DNA and human origins" Annual Review of Anthropology, vol. 17, pp. 127-143.

CANN, R., STONEKING, M. y WILSON, A. (1987).- "Mitochondrial DNA and human evolution". Nature, 325, pp. 31-36.

CORTES, M., MUÑOZ, V.E., SANCHIDRIÁN, J. L. y SIMON, M. D. (1996).- El Paleolítico en Andalucía: La dinámica de los grupos predadores en la Prehistoria andaluza. Ensayo de síntesis. Repertorio bibliográfico de 225 años de investigación (1770-1995). Córdoba.

DEMARS, P. Y. y HUBLIN J.J. (1989).- "La transition Neandertaliens/Hommes de type modern en Europe occidentale: aspects paleontologiques et culturels" en L'homme de Neandertal, vol. 7, La extintion, M. Otte (ed.), pp. 23-39. Lieja.

DÍAZ DEL OLMO, F. (1994).- "Interferencias sedimentarias y cambios climáticos en Gorham's Cave (Gibraltar)" en Gibraltar during the Quaternary, Rodríguez Vidal, J., Díaz del Olmo, F., Finlayson, C. y Giles Pacheco, F. (Eds.), AEQUA, monografías, 2, pp. 49-55. Sevilla.

EASTHAM, A. (1967).- "The avifauna of Gorham's Cave, Gibraltar". Bulletin of Institute Archaeology, 7, pp. 37-42. Londres.

FORTEA, F. J. (1985).- "El Paleolítico y el Epipaleolítico en la región central del Mediterráneo Peninsular. Estado de la cuestión" en Arqueología del País Valenciano: Panorama y Perspectivas, pp. 31-51. Instituto Juan Gil Albert. Alicante.

FORTEA, F. J. (1986).- "El Paleolítico Superior y el Epipaleolítico en Andalucía. Estado de la cuestión cincuenta años después" en Homenaje a Luis Siret, pp. 67-78. Sevilla.

FORTEA, J. y JORDÁ, F. (1976) "La cueva de Les Mallaetes y los problemas del Paleolítico Superior del Mediterráneo español". Zephyrus XXVI-XXVII, pp.129-166.

FUENTES, C. y MEIJIDE, M. (1975).- "Fauna fósil de la cueva de Horá (Granada)”. Estudios Geológicos, XXXI, pp. 777-784.

FUMANAL, M. P. (1985).- Sedimentología y clima en el País Valenciano. Las cuevas habitadas en el Cuaternario reciente. S.I.P. Serie de Trabajos Varios, 83. Valencia.

FULLOLA, J. Ma. (1979) Las industrias líticas del Paleolítico Superior Ibérico. S.I.P. Serie de Trabajos Varios, 60, 264 pags. Valencia.

FULLOLA, J. Ma (1983) "Le Paleolithique Superieur dans la zone Mediterraneenne Iberique". L'Anthropologie t. 87, pp. 339-352.

GARROD, D.A.E. (1928).- "Excavation of a Mousterian Rock-Shelter at Devil's Tower, Gibraltar". The Journal of the Royal Anthropological Institute of Great Britain and Ireland, LVIII, pp. 33-113.

HOWELLS, W. (1976).- "Explaining modern man: evolutionists versus migrationists". Journal of Human Evolution, 5, pp. 477-495. 
HOYOS, M. (1980).- La cueva de la Paloma (Soto de Regueras, Asturias). Excavaciones Arqueológicas en España, 116, Madrid.

HRDLICKA, A. (1927).- "The Neanderthal phase man". Journal of the Royal Anthropological Institute, 67, pp.249-269.

HUBLIN, J. J. (1996).- “Les derniers Néandertaliens” en L'Homme. Origine et Destinée. Colec. Les eclats du passé. pp. 55-64. Ed. Errance. París.

HUBLIN, J. J., BARROSO, C., MEDINA, F., FONTUGNE, M. y REYSS, J. L. (1995).- "The Mousterian site of Zafarraya (Andalucía, Spain): dating and implications on the palaeolithic peopling processes ofwestern europe". Compes Rendus de l'Academie des Sciences de Paris, t. 321, pp. 931-937. París.

IRWIN, H. T. y FRYXELL, R. (1969).- "Archaeologycal, geochronological and ecological investigation of Carigüela Cave, Granada, Spain". Research Proposal to National Science Foundation, pags. 52.

ITURBE, G.; FUMANAL, M. P.; CARRIÓN J. S.; CORTELL, E.; MARTÍNEZ, R.; GUILLEM, P. M.; GARRALDA, M. D. y VANDERMEERSCH, B. (1993).- "Cova Beneito (Muro, Alicante): Una perspectiva interdisciplinar'. Recerques del Museu d'Alcoi, 2, pp. 23-88.

JORDÁ, F. (1986).- "La ocupación más antigua de la Cueva de Nerja" en Trabajos sobre la Cueva de Nerja, 1, La Prehistoria de la Cueva de Nerja (Málaga). Paleolítico y Epipaleolítico, Jordá Pardo, J. (ed.), pp. 195-204. Málaga.

JORDÁ PARDO, J. F. (1986).- "Estratigrafía y sedimentología de la Cueva de Nerja (Salas de la Mina y del Vestíbulo)" en Trabajos sobre la Cueva de Nerja, 1, La Prehistoria de la Cueva de Nerja (Málaga). Paleolítico y Epipaleolítico, Jordá Pardo, J. (ed.), pp. 38-98. Málaga.

JORDÁ PARDO, J. F. y CARRAL, M. P. (1988).- "Geología y estratigrafía del yacimiento prehistórico de la Cueva de Ambrosio". BAR International Series 462, pp. 19-40. Oxford.

MAROTO, J. (1994).- El pas del paleolític mitjà al paleolític superior a Catalunya i la seva interpretació dins del context geografic franco-iberíc. Tesis Doctoral, Universidad de Gerona, Gerona.

MAROTO, J. y SOLER, N. (1990).- "La rupture entre le Paléolithique moyen et le Paléolithique supérieur en Catalogne" en "Paléolithique moyen récent et Paléolithique supérieur ancien en Europe. Ruptures et transitions: examen critique des documents archéologiques". Actes du Colloque international de Nemours, Farizy, C. (ed.), Mémoires du Musée de Préhistoire d'Ile de France, 3, pp. 263-265. París.

MAROTO, J., SOLER, N. y FULLOLA, J. M. (1996).- "Cultural change between Middle and Upper Palaeolithic in Catalonia" en The last neandertals the first anatomically modern humans: A tale about the human diversity. Cultural Change and Human evolution: the crisis at $40 \mathrm{ky} \mathrm{BP}$, Carbonell, E. y Vaquero, M. (ed.), pp. 219-250. Barcelona.

MARQUES, I. y FERRER, J. E. (1991).- "Hallazgo de industria Solutreogravetiense en el Bajondillo (Torremolinos, Málaga)". Baetica 13, pp. 137-146.

MEDINA, F., BARROSO, C., SANCHIDRIÁN, J. L. y RUIZ BUSTOS, A. (1986).- "Avance al estudio de los niveles musterienses de la cueva del Boquete de Zafarraya (Alcaucín, Málaga). Excavaciones de 1981-83" en Homenaje a Luis Siret, pp. 94-105. Sevilla.

OBERMAIER, H. (1925).- El Hombre Fósil Comisión de Investigaciones Paleontológicas y Prehistóricas. Mem. 9, $2^{\text {a }}$ ed. Madrid.

OBERMAIER, H. (1934).-“Estudios prehistóricos en la provincia de Granada" Anuario del Cuerpo Facultativo de Archivos, Bibliotecas y Arqueólogos, 1, pp. 225-273.

PANIAGUA, J. P. (e. p.).- "Sobre el Auriñaciense de la Cueva de Ambrosio (Vélez-Blanco, Almería)" en Actas XXIV Congreso Nacional de Arqueología. Cartagena (1997).

PELLICER, M. (1964). - "El Neolítico y el Bronce de la Cueva de la Carigüela de Piñar (Granada)". Trabajos de Prehistoria, XV, pp. 7-71. 
PÉREZ RIPOLL, M. (1986).- “Avance al estudio de los mamíferos de la Cueva de Nerja” en Trabajos sobre la Cueva de Nerja, 1, La Prehistoria de la Cueva de Nerja (Málaga). Paleolítico y Epipaleolítico, Jordá Pardo, J. (ed.), pp. 99-106. Málaga.

RAMOS MUÑOZ, J. (1994).- "El Paleolítico Superior en la Bahía de Málaga. Reflexiones para un necesario debate". Spal 3, pp. 73-85.

RIPOLL PERELLÓ, E. (1961).- "Excavaciones en Cueva Ambrosio (Vélez-Blanco, Almería). Campañas 1958-1960". Ampurias, XXII-XXIII, pp. 31-45.

RIPOLL LÓPEZ, S. (1988) “La Cueva de Ambrosio (Vélez Blanco, Almería) y su posición cronoestratigráfica en el Mediterráneo Occidental" BAR International Series 462, pags. 596, Oxford.

RIPOLL LÓPEZ, S.; MUÑOZ, F. J.; PANIAGUA, J. P.; AMAYA, C. y CALLEJA, F. (e. p.) "Nuevas aportaciones de la Cueva de Ambrosio: el arte rupestre" en Actes du Colloque International El Mon mediterrani després del Pleniglacial (18.000-12.000 B. P.). Bañolas, 1995. Gerona.

RODRÍGUEZ, T. y MARTÍN, A. (1979).- "Avance al estudio ecológico de Cueva Horá (Darro, Granada)". Antropología y Paleoecología Humana, 1, pp. 75-79.

RUIZ, B. y LEIVA, J. (1979).- "El taller de sílex Paleolítico de El Chorro (El Burgo, Málaga)”. Mainake 1, pp.5-27.

SANCHIDRIÁN, J. L. (1994). - "Arte paleolítico de la zona meridional de la Península Ibérica”. Complutum, 5, pp. 163-196.

SIRET, L. (1893).- "L’Espagne Prehistorique”. Revue des Questions Scientifiques, 78 pags.

SIRET, L. (1933).- "Clasífication du Paleolithique dans le Sud-Est de l'Espagne". XV Congres International d'Anthropologie et Archéologie Préhistorique, Portugal 1930, pp. 287-294. París.

SOLER, N. y MAROTO, J. (1990).- "El final del Paleolític Mitjà i l'inici del Paleolític Superior Ibérique". Cypsela, VIII, pp. 7-13.

SOLER, N. y MAROTO, J. (1993).- "Les nouvelles datacions de l'Aurignacien dans la Péninsule Ibérique" en Actes du XIIe Congrès International des Sciences Préhistoriques et Protohistoriques, 2, Institut Archéologique de l'Académie Slovauqe des Sciences, pp.162-173. Bratislava (1991).

STONEKING, M. y CANN, R. (1989).- "African origin human mitochondrial DNA" en The Human Revolution: Behavioural and Biological Perspectives in the Origins of Modern Humans, vol. 1. Mellars, P. y Stringer, C. (eds.), Edinburgh University Press. pp. 17-30. Edinburgo.

STRINGER, C. (1988).- "The dates of Eden". Nature, vol. 331, pp. 565-566.

STRINGER, C. y ANDREWS, P. (1988).- "Genetic and fossil evidence for the origin of modern humans". Science, 239, pp. 1263-1268.

STRINGER, C. y GAMBLE, C. (1993).- In search of the Neanderthals. solving the Puzzle of Humans Origins. Thames and Huson. Londres.

SUCH, M. (1920).- "Avance al estudio de la caverna "Hoyo de la Mina" en Málaga". Boletín de la Sociedad Malagueña de Ciencias. Málaga.

TERRADAS, X., MORA, R., MARTÍNEZ, J. y CASELLAS, S. (1993).- "La Roca dels Bous en el contexto de la transición Paleolítico Medio-Superior en el NE de la Península Ibérica" en El Origen del Hombre Moderno en el Suroeste de Europa, Cabrera, V. (ed.), UNED, pp. 247-253. Madrid.

TORO, I. y ALMOHALLA, I. (1979).- "Industrias del Paleolítico Superior en Granada". Cuadernos de Prehistoria de la Universidad de Granada, 4, pp. 1-20.

VALLOIS, H. (1954).- "Neanderthals and presapiens". Journal of the Royal Anthropological Institute, 84, pp. 1-20.

VEGA, L. G. (1980).- "El Musteriense de la Cueva de Zájara I (Cuevas de Almanzora, Almería)". Trabajos de Prehistoria, 37, pp. 11-64.

VEGA, L. G. (1988).- El Paleolítico Medio del Sureste español y Andalucía Oriental. Serie Tesis Doctorales, Universidad Complutense. Madrid. 
VEGA, L. G. (1990).- "La fin du Paleolithique Moyen au sud de l'Espagne: ses implications dans le contexte de la Péninsule Iberique" en Paléolithique moyen récent et Paléolithique supérieur ancien en Europe. Ruptures et transitions: examen critique des documents archéologiques. Actes du Colloque international de Nemours, Farizy, C. (ed.), Mémoires du Musée de Préhistoire d’Ile de France, 3, pp. 169-180. París. VEGA, L. G. (1993).- "El tránsito del Paleolítico Medio al Paleolítico Superior en el Sur de la Península Ibérica" en El origen del Hombre Moderno en el Suroeste de Europa, Cabrera, V. (ed.), pp. 147-170. Madrid.

VEGA, L. G., HOYOS, M., RUIZ-BUSTOS, A. y LAVILLE, H. (1988).- "La sequence de la grotte de la Carihuela (Piñar, Grenade): Chronostratigraphie et paleoecologie du Pléistocène Superieur du Sud de la Peninsule Iberique" en L'Homme de Neándertal, vol. 2, La subsistance, Otte, M. (ed.), pp.154-153. Lieja.

VEGA, L. G. y CARRIÓN, J. S. (1993).- "Secuencia paleoclimática y respuesta vegetal durante el Pleistoceno Superior de la cueva de la Carihuela (Piñar, Granada, SE de España)" en Estudios sobre Cuaternario. Medios sedimentarios. Cambios ambientales. Hábitat Humano, M. P. Fumanal y J. Bernabeu (eds.), pp. 131-138. Valencia.

WAETCHER, J. (1951).- "Excavations at Gorham's Cave, Gibraltar". Proceeding of the Prehistoric Society vol. 17, pp. 83-92.

WAETCHER, J. (1953).- "The excavations of Gorham's Cave and its relation to the prehistory of southern Spain". Archivo de Prehistoria Levantina 4, pp. 21-24.

WAETCHER, J. (1964).- "The excavation of Gorham's Cave, Gibraltar, 1951-1954". Bulletin Institute of Archaeology 4, pp. 189-222.

WOLPOFF, M. H. (1986).- "Describing anatomically modern Homo sapiens: a distinction without a definable difference" en "Fossil man. New facts, New Ideas. Papers in Honor of Jan Jelinek's Life Aniversary", Novotny, V. V. y Mizerova, A. (eds.), Anthropos, 23, pp. 41-53.

WOLPOFF, M. H. (1989).- "Multiregional evolution: The fossil alternative to Eden" en The Human Revolution: Behavioural and Biological Perspectives in the Origins of Modern Humans, vol. 1, pp. 62-108, Mellars, P. y Stringer, C. (eds.), Edinburgh University Press. pp. Edinburgo.

WOLPOFF, M. H., WU XINZHI, y THORNE, A. G. (1984).- "Modern Homo sapiens sapiens origins: A general theory of hominid evolution involving the fossil evidence from East Asia" en The origins of modern humans: a world survey of the fossil evidence, Smith, F. H. Spencer, F. (eds.), New York: Alan R. Liss. pp. 411-483. New York.

WOLPOFF, M. H., THORNE, A. G., SMITH, F. H., FRAYER, D. W. y POPE, G. G. (1994).- "Multirregional evolution: a world-wide source for modern human populations" en Origins of Anatomically Modern Humans, Nitecki, M. H. y Nitecki, D. V. (eds.), Plenum Press, pp. 175-199. New York.

ZEUNER, F. (1953).- "The Chronology of the Mousterian al Gorham's Cave, Gibraltar". Proceeding of the Prehistoric Society vol. 19, pp. 180-188.

ZEUNER, F. y SUTCLIFFE, A. (1964).- "Preliminary report on the mamalia of Gorham's Cave". Bulletin Institute of Archaeology, 4, pp. 213-218.

ZILHAO, J. (1993a).- "Le passage du Paléolithique moyen au Paléolithique supérieur dans le Portugal" en El Origen del Hombre Moderno en el Suroeste de Europa, Cabrera, V. (ed.), pp. 127-146. Madrid.

ZILHAO, J. (1993b).- "Aurignaien et Gravettien au Portugal" en Actes du XIIe Congrès International des Sciences Préhistoriques et Protohistoriques, 2, Institut Archéologique de l'Académie Slovauqe des Sciences, pp.154-162, Bratislava (1991). 